\title{
Research on Teaching Reform of Material Science Basic Courses Based on MOOC Teaching Comprehensive Platform
}

\author{
Jianfeng Yang \\ Zhengzhou University, Material Science and Engineering School, Zhengzhou, Henan, China, 450001
}

Keywords: MOOC: Teaching Integrated Platform: Material Science: Teaching Reform

\begin{abstract}
With the rapid development of modern information science and technology in our country, MOOC began to play an increasingly important role in the teaching of basic materials science in China. MOOC mainly through modern information technology, not only can develop and use existing the teaching resources of the basic course of material science can also optimize the teaching process of the basic course of materials science in China, which is of great significance to enhance the quality and benefit of the basic teaching of material science. Therefore, this paper mainly aims at the concept of MOOC and the function of the comprehensive platform of MOOC teaching for the basic course teaching of materials science, and puts forward the concrete measures and methods of teaching reform of materials science basic course of MOOC teaching comprehensive platform. Based on the comprehensive teaching platform of Mu science, this paper provides some reference and reference for teaching reform of materials science basic course.
\end{abstract}

\section{Introduction}

With the rapid development of modern information science and technology in China, our educational methods are constantly being updated and reformed. As a new teaching method, MOOC has entered into the teaching work of modernization in our country. It is a video as a carrier, around the teaching work of a knowledge point, and then carrying out a scientific and technological teaching activity. In today's "Mu era" environment, more and more teachers in China began to use MOOC technology for new teaching work. Which can focus on the teaching of basic materials in the teaching of materials, but also through the use of MOOC, this diversified, modern teaching methods, so as to optimize Chinese materials science basic course teaching content and methods, enrich Chinese material science the teaching of the course to create a material science curriculum active and benign classroom environment, we can see, MOOC in Chinese materials science basic course teaching work in the use of a very important position.

\section{The Concept of MOOC}

MOOC is large-scale open online self-study courses, in fact, is a "flip classroom" teaching mode. $\mathrm{Mu}$ class mainly refers to the use of modern information technology, in accordance with certain cognitive laws, to fragmented learning content, process and expansion of the material in the form of a structured new digital teaching resource. In simple terms, MOOC is actually an online teaching platform that covers the knowledge of students' learning needs. MOOC is characterized by its strong intuition, prominent themes, diverse types, short time, real and interactive can be generated strong and so on and it is very easy to make students highly focused attention. Students can also according to their own needs, anytime, anywhere access and re-use $\mathrm{Mu}$ class teaching integrated platform, making the students no longer limited to the traditional classroom teaching, but to achieve the students anytime, anywhere to strengthen the purpose of learning results. Especially in the teaching of materials science basic course in our country, MOOC as a supplement and auxiliary means, through the more personalized and effective materials science basic course teaching 
activities, so that students can be more conscious, active and convenient materials science - based curriculum. Material science teachers can pass the Mu class, with a new perspective to determine the learning status of each student, changing the past in Chinese traditional materials science basic course teaching work can not perceive the students a deeper level of learning problems, so that teachers can a good understanding of each student's real learning situation, and its individualized teaching, for each student to carry out personalized teaching services [1].

\section{The Role of MOOC Teaching Integrated Platform for Materials Science Basic Courses Teaching}

MOOC through the modernization of scientific and technological strength in the promotion of Chinese basic science and materials science teaching work has a very important significance, $\mathrm{Mu}$ class not only allows teachers to teach at any time, but also for the basic science materials teaching materials to bring unlimited vitality and vitality.

Concentrate Knowledge Points and Save Teaching Time. MOOC in the modern materials science basic course teaching work with concentrated knowledge points, saving the effect of theoretical teaching time. Due to the limited time of classroom teaching in Chinese materials science curriculum, it is almost impossible for teachers to complete all kinds of teaching tasks within the stipulated time, but MOOC has changed the past Full of teaching mode. So that teachers can only in just ten to twenty minutes to enrich the teachers to explain all the knowledge points, and timely, intuitive, repeated display to the students, can greatly improve the efficiency of teaching teachers. MOOC through the students to make up for the defects of thinking and knowledge loopholes can effectively enhance the students of materials science basic course learning interest, active material science basic course teaching classroom atmosphere, thus greatly speeding up the material science basic course teaching progress [2].

Various Forms and Enhance Students' Interest in Learning. There are some teaching materials which are not easy to express in language teaching in the basic teaching of materials science. The material science teachers in our country can make use of the appropriate materials and make good materials and materials, and improve the materials science foundation the effect of teaching effectiveness. Teachers through the MOOC teaching integrated platform to the students to visually strong impact, fun and entertainment, so that students take the initiative to participate in the basic materials science course learning, so that students immersed in the relaxed, pleasant material science basic course learning atmosphere and then improve the basic science materials teaching the effectiveness of the work.

Provide an Exchange Learning Platform. In some cases, the teacher's explanation may not be clear enough, many students may have missed these key points of knowledge, but because of the limitations of time and space in the teaching of basic materials science in our country, teachers can teach through the comprehensive classroom, so that each student online to repeatedly watch and learn these knowledge points, as well as students in the classroom cannot fully grasp the knowledge points, students can also be anytime, anywhere through the MOOC to carry out repeated learning, and in the process of learning and teachers to communicate, so as to learn the classroom did not learn the knowledge points, and improve the lack of learning.

Show the Style of Outstanding Teachers. In the past, under the traditional teaching model of material science basic course, many excellent teachers have the opportunity to share their teaching process. However, with the rapid development of modern information science and technology in our country, many excellent teachers in our country can pass the lesson to their courseware, works, teaching content and teaching process and so shared to the majority of learners, so that excellent materials science basic teaching resources to share around the world, so that more people benefit. This is not only a show of teachers to help schools establish a good brand image, teachers can also through the MOOC find their own shortcomings and deficiencies, and to improve, so as to better enhance the teaching level of teachers. 


\section{The Teaching Reform of Materials Science Basic Courses Based on MOOC Teaching Integrated Platform}

Nowadays, the comprehensive platform of MOOC teaching has effectively entered the teaching work of modernization in our country, and it is of great significance to promote the teaching resources of quality courses in our country, improve the quality of personnel training through modern information technology, and realize the construction of service learning society. In today's Ministry of Education advocated Mu class teaching integrated platform environment, more and more teachers in China began to invest in the construction of a comprehensive platform for teaching. Through the exploration and practice of the reform of teaching system of material science basic course based on the comprehensive platform of MOOC teaching, we can carry out comprehensive reform and innovation through the teaching methods, teaching contents, teaching practice mode and teaching methods of basic course of materials science, In order to achieve the ability to guide students to creatively use knowledge and ability to independently identify problems, research problems and solve problems.

Teaching Method Reform. As one of the core elements of modern education and teaching system in our country, the teaching method is especially suitable for the teaching of the basic course of materials science, so that a course involving a wide range of complex and complex curriculum reform. This is mainly due to the basic science of materials science teaching is often difficult to pass textbooks can be simple and clear to explain clearly. Therefore, based on the teaching system of materials science basic course based on MOOC teaching comprehensive platform, through the study of the problems and causes of teaching methods of material science basic course based on MOOC teaching comprehensive platform, we adopt new experience, ideas and methods, So that our teachers face the changes in the functions and roles of teachers, in response to the call of the new era, from the simple knowledge of the transfer of teachers gradually transformed into teaching designers, organizers and guides. Through the re-integration and re-development of the teaching materials and teaching resources of the materials science basic course based on the comprehensive teaching platform of Mu-class teaching, we can select the content that can stimulate the students' interest from the teaching task, so as to ensure the comprehensive platform based on the teaching Materials science basic course teaching work more purposeful, planned, systematic development to achieve a comprehensive and effective teaching methods to enhance students' learning outcomes.

Teaching Content Reform. In the past, Chinese materials science basic course teaching too much emphasis on the material science of the theory, but will make the basic science materials teaching work stagnant, and even lead to material science basic course teaching effect of a straight line. Therefore, it is necessary to analyze the logical main line of the basic course of material science based on the teaching content of material science basic course based on MOOC teaching comprehensive platform, and highlight the curriculum focus and difficulty based on the comprehensive platform of MOOC teaching, and design more characteristic a variety of teaching content teaching program; to promote the teaching of the synergy between the overall and the overall optimization; rational use of teaching methods, teaching art, system design teaching content. Through the introduction of the case teaching method in the teaching content of the basic science course based on the MOOC teaching comprehensive platform, it is necessary to select and formulate the basic content of the material science course based on the comprehensive teaching platform of MOOC not only enrich the teaching content, To guide students to creatively use knowledge and ability to achieve the purpose of improving the teaching effectiveness of basic materials science curriculum.

Curriculum Reform of Teaching Practice. Based on the comprehensive teaching platform of materials science, the teaching practice mode of material science basic course is mainly from the aspects of "teaching" and "learning". "Teaching" refers to the teachers' focus and difficulty of basic teaching of materials science. Target decomposition refines the target, for different issues choose different teaching methods. According to the new and old knowledge of the internal links, the organization of students, students and teachers in the MOOC teaching integrated platform for 
interactive exchanges to promote the enthusiasm of students to learn. "Learning" is through the mobilization of student activities, so that students from the past to simply learn to listen to the participants into the participants, and teachers through the students in the MOOC teaching comprehensive platform for group discussion on the way, not only intangible to improve student learning And make full use of the interactive teaching of MOOC teaching comprehensive platform to guide and encourage students to participate in the personalized materials science basic course teaching, thus enhancing the students' initiative to explore consciousness, innovation consciousness and practical ability.

Teaching Reform. Based on the comprehensive teaching platform of materials science, the reform of teaching methods of material science basic course is mainly based on the basic teaching and research resources of materials science basic course, supported by the general teaching platform of MOOC class, the use of Dreamweaver, Flash, Fireworks and other web production, animation design and image processing of new technologies, will be complicated with the development of new materials, such as the development of new materials, the use of a variety of Powerpoint, 3Dmax Flash and other modern media technology and text, formulas, illustrations, animation, photos, video and other information organically together to fully demonstrate the traditional teaching methods difficult to express the material science course teaching process [3].

\section{Conclusion}

MOOC is now as a new way of teaching, is to urge the teaching concept and the way students learn the change, especially in Chinese materials science basic course teaching work, MOOC has to enhance the material science basic course teaching work effect, but this requires our teachers to change the traditional materials science basic course teaching concept to enhance their professional skills level, in the basic course of materials science teaching process to make full use of MOOC, so as to stimulate students to learn interest, to achieve rich classroom teaching, optimization the goal of teaching effect of basic course of material science.

\section{References}

[1] Xiang Hongnian "New normal" under the material science teaching skills training "four micro-integration" model - Hubei University of Science and Technology Institute of Art and Design as an example [J]. .Journal of Hubei Normal University (Philosophy and Social Sciences Edition) 2015 (9): 58-59.

[2] Shu Yanhong. University materials science Mu class development significance[J]. Materials Science Education Research, 2015, (1): 62-64.

[3] Wu Shan. Mu class on the improvement of teaching effectiveness of thinking[J]. Science and Technology Guide, 2013, (10): 94-96. 